\title{
Changes in the basal dendrites of cortical pyramidal cells from alcoholic patients-a quantitative Golgi study
}

\author{
Clive Harper, Darren Corbett
}

\begin{abstract}
Although a variety of pathological changes have been described in the brains of chronic alcoholic patients, there have been no studies which have addressed the question of alterations in cortical neuronal dendritic arborisation. Loss of neurons from the superior frontal gyrus and shrinkage of neurons from both the superior frontal gyrus and motor cortex has been documented in chronic alcoholic patients; these areas were chosen for this study. Using a modified rapid Golgi technique the basal dendritic arborisation of layer III pyramidal neurons was compared in 15 male alcoholic patients and 15 age-matched male controls. All parameters measuring basal dendritic arborisation were significantly less in the alcoholic cases for both the superior frontal and motor cortices. Changes in the arbor are in the terminal branches, which is consistent with other models of dendritic plasticity. Such changes may explain both permanent and reversible functional deficits in chronic alcoholic patients.
\end{abstract}

A considerable volume of information has recently become available on the effects of chronic high levels of alcohol consumption on the human central nervous system. A loss of brain tissue in chronic alcoholics has been well documented in studies of brain weights ${ }^{12}$ and the measurements of the pericerebral space. $^{3}$ These data support computerised tomographic (CT) studies which show brain shrinkage in alcoholic patients. ${ }^{4}$ Many of these patients have frontal lobe cognitive deficits. Stereometric measurements of the volumes of cortical grey matter, white matter and basal ganglia have shown that this loss of tissue is predominantly from the white matter. However, although cortical grey matter volumes are normal in alcoholics, ${ }^{6}$ quantitative studies on neuronal number and size have revealed alterations in the cortex of alcoholics. Neuronal numbers are significantly reduced in the superior frontal cortex ${ }^{7}$ but unaltered in the motor, frontal cingulate and temporal cortices. ${ }^{8}$ Shrinkage of neurons is evident in the superior frontal, motor and frontal cingulate cortices. ${ }^{8}$ Further analysis of the neuronal loss in the superior frontal cortex established that the large neurons, those greater than $90 \mu \mathrm{m}^{2}$ in the profile area, were decreased in alcoholics ${ }^{9}$ and these almost certainly represent pyramidal neurons.

The pyramidal neurons of the cerebral cortex are numerous and easily identified. They have a characteristic apical dendrite which is orientated towards the cortical surface and a prominent basal dendritic network. This network provides an enormous membrane surface area for the reception of information and interaction with other neurons. The maturaion of the basal dendritic network proceeds nto adolescence and there is good evidence that the process of progressive plastic dendritic change may continue indefinitely. ${ }^{10}$ Regressive changes can also occur and these appear to be reflected in both apical and basal dendrites. ${ }^{1112}$

Studies of alterations of dendritic arborisation in association with alcohol toxicity have largely utilised animal models. ${ }^{1314}$. Cerebellar Purkinje cells have been studied in rats ${ }^{15} 16$ and humans, ${ }^{17}$ both showing a contraction of the arbor. To our knowledge no quantitative Golgi studies of the arborisation of cortical neurons in chronic alcoholics have previously been carried out.

\section{Materials and methods}

The brains of 15 alcoholics and 15 controls were used in this study. These were obtained from necropsies performed in collaboration with the forensic pathologists of the Perth City Coroner's Department. The cases were all males and the controls were matched for age and postmortem delay to the alcoholics. Five of the controls had been teetotal and the remainder drank less than $20 \mathrm{~g}$ of alcohol per day. The alcoholic patients drank more than $120 \mathrm{~g}$ of alcohol per day. The information to allow categorisation of cases into "control" and "alcoholic" had been obtained from clinical notes available from previous admissions to the teaching hospitals of Perth, the results of detailed questionnaires on alcohol intake and the nutritional state provided by relatives of the deceased, and reports concerning the circumstances of death.

Each case had a complete necropsy and microscopic examination of the tissues including the liver and brain. Patients who had a history of, or showed pathological evidence of neurological diseases other than those associated with alcoholism, were excluded. No cases with evidence of brain pathology (for example, infarcts, contusions) were included. Three of the alcoholics had Wernicke's encephalopathy and two had pathologically con- 
Figure 1 Golgi impregnated neurons from layer III of the superior frontal cortex of a control case showing apical dendrites $(A)$ and basilar dendritic arbor (arrows) $(\times 600)$. firmed cirrhosis of the liver. All cases were given a code which was not broken until they had been studied. Most of these cases had been used in brain volume studies ${ }^{36}$ and neuronal count studies. ${ }^{7-9}$ Each brain had been processed according to the protocol outlined in those papers. ${ }^{367}$

The left hemispheres were stored in $10 \%$ formyl saline for over 15 months before the removal of one block measuring approximately $20 \mathrm{~mm}$ by $20 \mathrm{~mm}$ by $3 \mathrm{~mm}$ from each of the left superior frontal gyrus (LFS; area 8 according to Brodmann's classification ${ }^{18}$ ) and the left motor cortex (Brodmann's area 4). They were Golgi impregnated using a modification of the Keleman and Yamada technique, as described by Mehraein et al. ${ }^{19}$ Following this the blocks were dehydrated and embedded in soft paraffin in the conventional manner.

The blocks were sectioned on a Polycut sledge microtome. Thick sections of 100 micrometers were taken and mounted on glass slides. These were dewaxed and mounted conventionally under cover slips. After every two of these thick sections, a section of 20 micrometers was taken. These were counterstained with celestine blue and haematoxylin and eosin, and were used to help identify the layers of the cortex in the thicker sections.

Neurons were randomly selected for study if they met the following criteria: the neuron was of the pyramidal type, the cell body was in layer III of the cortex, the cell body was of average size, the dendritic arbor appeared to be fully stained and each branch could be followed to its termination or to where it was cut by the microtome knife. A representative photomicrograph of a control case is shown in fig 1 . No attempt was made to exclude neurons whose dendritic arbor was cut by the microtome knife. The thickness of the cortex and the depth of the cell from the pial surface were measured for each cell.

Five neurons were studied from each block and only the basal dendrites of each neuron were studied. They were drawn using a camera lucida at a magnification of $\times 1000$. Figure 2 shows typical examples of drawings of the basal dendritic network of layer III pyramidal neurons from the frontal superior cortex in a control (A) and an alcoholic (B) case. As each

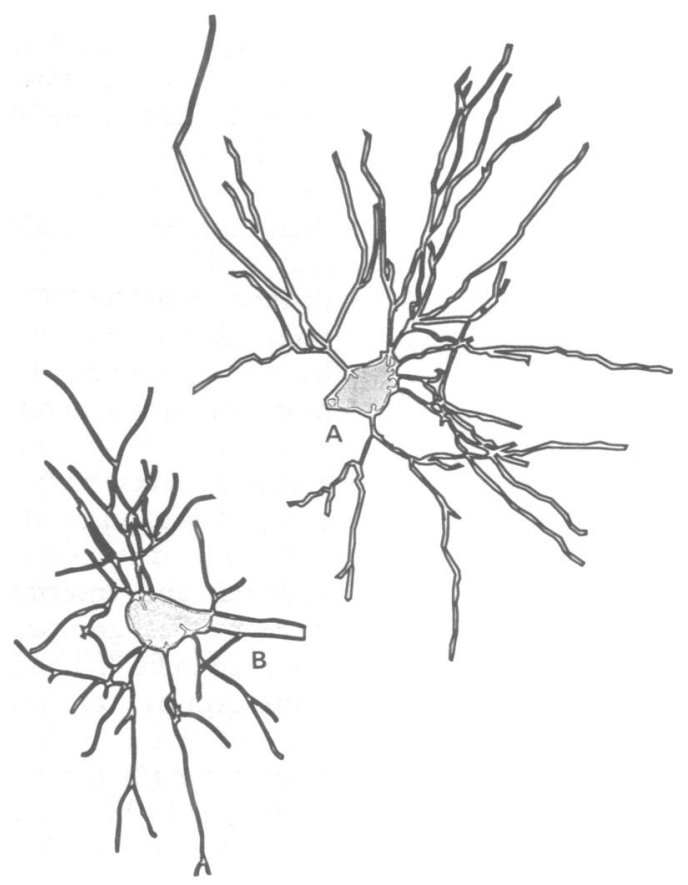

Figure 2 Typical examples of the camera lucida drawing of the basal dendritic arbor of layer III pyramidal neurons from the superior frontal cortex in a control ( $A)$ an alcoholic $(B)$ case. The hatched area represents the neuronal cell body.

branching point or a branch termination was encountered, the fine focus reading was noted on the drawing. An approximation of each segment length was then calculated using Pythagorean theorem, taking the length as measured off the drawing as the horizontal distance and the difference in the fine focus readings of the two ends of each segment as the vertical distance. Where a branch was wavy in a vertical plane the fine focus readings of the crests and troughs were noted on the drawings and these were taken into account in the calculation of segment length. The effect of curvature in the horizontal plane on segment length were considered as these were easily ascertained from the drawings.

The order (assigned in a centrifugal direction, as in fig 3) of each segment was noted as was its position (whether an intermediate, terminal or cut branch, as labelled in fig 3).

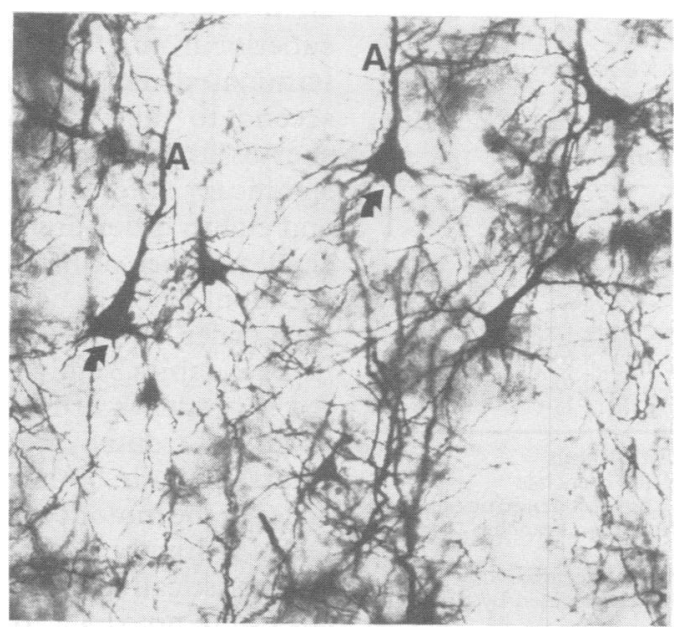

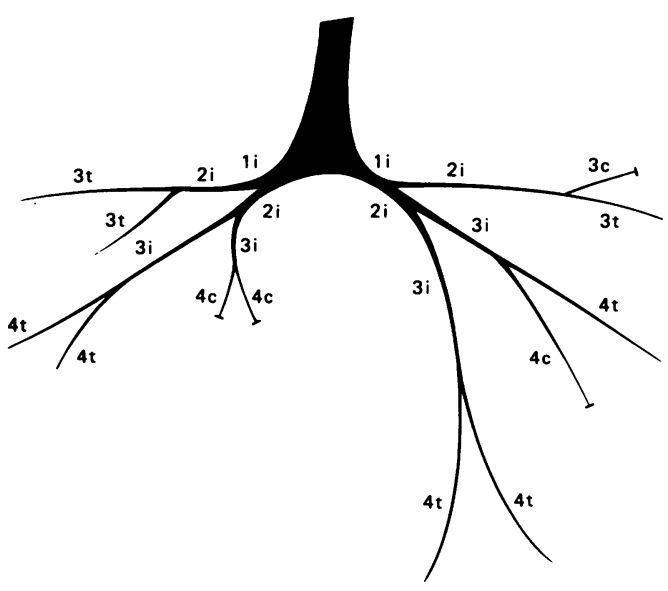

Figure 3 Method of assigning order and position to a branch. $i=$ intermediate branch, $t=$ terminal branch, $c$ $=$ branch was cut by the microtome knife. 
These data, along with each segment's length, was stored in a spreadsheet grouped according to the cell from which they came.

The following parameters were determined for each neuron: total basal dendritic length, total number of dendritic branches, the maximal width of the basal dendritic field (the distance between the most widely separated points on the field), the number of branches cut by the microtome knife (assuming that the more extensive dendritic arbors will be cut more often by the microtome knife) and the area of each cell body. The latter was measured using a Watanabe digitiser tablet and computer. Dendritic segments were grouped into terminal and intermediate segments, which were further grouped according to order as assigned in fig 3 . The average lengths of each of these groups were compared for the controls and alcoholics. The overall mean terminal branch length for each case was also determined and the groups compared. The cut branches were excluded from these comparisons. Statistics were performed using the SPSS-X program.

\section{Results}

Normal distribution of data was tested by using the Kolmogorov-Smirnov goodness of fit test. A normal Gaussian distribution was found for all parameters except the terminal branch length by order (mean terminal branch length was normally distributed), therefore statistics were performed using the Students' $t$ test. The Mann-Whitney non-parametric test of significance was used for the terminal branch length by order (tables 3, 4).

The mean (SEM) ages of control and alcoholic groups were 61 (13) years and $60(10)$ years respectively. The mean (SEM) postmortem delays (time between death and necropsy) were 26 (9) hours and 24 (10) hours for the control and alcoholic groups respectively. There was no significant difference in either of these parameters. The mean thickness of the cortex and depth of the cell in the cortex did not differ for the two groups.

Table 1 summarises the means and standard deviations for the total basal dendritic length, number of dendritic branches, the maximal

Table 1 Dendritic arborisation measurements in control and alcoholic groups

\begin{tabular}{|c|c|c|c|}
\hline \multirow[b]{2}{*}{ Parameter } & \multicolumn{3}{|c|}{ Superior Frontal Cortex } \\
\hline & $\begin{array}{l}\text { Control } \\
n=15 \\
\text { mean (SEM) }\end{array}$ & $\begin{array}{l}\text { Alcoholic } \\
n=15 \\
\text { mean (SEM) }\end{array}$ & $P<$ \\
\hline $\begin{array}{l}\text { TDL }(\mu \mathrm{m}) \\
\text { Branches } \\
\text { Width }(\mu \mathrm{m}) \\
\text { Cut branches } \\
\text { Term }(\mu \mathrm{m})\end{array}$ & $\begin{array}{r}1787(108) \\
59(1 \cdot 8) \\
246(7 \cdot 8) \\
8(1 \cdot 0) \\
42(1 \cdot 8)\end{array}$ & $\begin{array}{r}1399(85) \\
52(2 \cdot 1) \\
211(8 \cdot 6) \\
5(0 \cdot 6) \\
36(2 \cdot 1)\end{array}$ & $\begin{array}{l}0.007 \\
0.028 \\
0.005 \\
0.051 \\
0.036\end{array}$ \\
\hline $\begin{array}{l}\text { TDL } \\
\text { Branches } \\
\text { Width } \\
\text { Cut branches }\end{array}$ & \multirow{2}{*}{\multicolumn{3}{|c|}{$\begin{array}{l}=\text { total basal dendritic length } \\
=\text { number of dendritic branches } \\
=\text { maximum width of basal dendritic field } \\
=\text { number of dendritic branches cut by } \\
\text { microtome } \\
=\text { mean terminal branch length } \\
=\text { significance value determined by Students' } \\
t \text { test }\end{array}$}} \\
\hline $\begin{array}{l}\text { Term } \\
\mathbf{P}\end{array}$ & & & \\
\hline
\end{tabular}

Table 2 Dendritic arborisation measurements in control and alcoholic groups

\begin{tabular}{|c|c|c|c|}
\hline \multirow[b]{2}{*}{ Parameter } & \multicolumn{3}{|l|}{ Motor Cortex } \\
\hline & $\begin{array}{l}\text { Control } \\
n=12 \\
\text { mean (SEM) }\end{array}$ & $\begin{array}{l}\text { Alcoholic } \\
n=12 \\
\text { mean (SEM) }\end{array}$ & $P<$ \\
\hline $\begin{array}{l}\text { TDL }(\mu \mathrm{m}) \\
\text { Branches } \\
\text { Width }(\mu \mathrm{m}) \\
\text { Cut branches } \\
\text { Term }(\mu \mathrm{m})\end{array}$ & $\begin{array}{r}1591(70) \\
52(1 \cdot 7) \\
242(7 \cdot 9) \\
9(0 \cdot 8) \\
45(2 \cdot 2)\end{array}$ & $\begin{array}{r}1228(42) \\
46(1 \cdot 7) \\
203(8 \cdot 8) \\
6(0 \cdot 6) \\
36(1 \cdot 8)\end{array}$ & $\begin{array}{l}0.001 \\
0.025 \\
0.004 \\
0.008 \\
0.004\end{array}$ \\
\hline $\begin{array}{l}\text { TDL } \\
\text { Branches } \\
\text { Width } \\
\text { Cut branches }\end{array}$ & \multirow{2}{*}{\multicolumn{3}{|c|}{$\begin{array}{l}=\text { total dendritic length } \\
=\text { number of dendritic branches } \\
=\text { maximum width of basal dendritic field } \\
=\text { number of dendritic branches cut by } \\
\text { microtome } \\
=\text { mean terminal branch length } \\
=\text { significance value determined by Students' } \\
t \text { test }\end{array}$}} \\
\hline $\mathbb{T}_{\mathbf{P}}^{\text {Term }}$ & & & \\
\hline
\end{tabular}

width of the basal dendritic field, number of cut dendritic branches and the mean terminal branch length for neurons from the superior frontal cortex in the control and alcoholic groups. All of the parameters were significantly smaller in the alcohol group when compared with the controls. The mean (SEM) neuronal cell body area was $240\left(60 \mu \mathrm{m}^{2}\right)$ for controls and $220\left(72 \mu \mathrm{m}^{2}\right)$ for alcoholics and these were not significantly different.

Table 2 summarises the same data for the neurons from the motor cortex. Despite repeated attempts, Golgi impregnations of four of the motor cortical blocks were of insufficient quality to permit the quantitation of five pyramidal neurons from layer III. Two of these four were a matched pair, the other two were not and their age and postmortem delaymatched pair (despite successful impregnation) was omitted. Thus three pairs of cases had to be discarded from this part of the study. However, in spite of this, all of the parameters which give a measure of the basal dendritic arborisation were significantly smaller in the alcoholic group. The mean (SEM) neuronal cell body area was $205\left(57 \mu \mathrm{m}^{2}\right)$ and $191\left(53 \mu \mathrm{m}^{2}\right)$ for the control and alcoholic groups respectively. These were not significantly different.

The mean terminal branch length for the alcoholic group is significantly smaller in both the frontal and motor cortices. Tables 3 and 4 provide data on the mean lengths of the terminal dendritic branches by order. Because there were so few branches of order seven and eight these were combined. In both the superior frontal and motor cortices the mean terminal dendritic branch lengths from the second to the sixth order were significantly shorter in the alcoholic group. There was no significant difference for the combined seventh and eighth order branches, possibly due to the small number of branches of these orders. In addition, the number of terminal branches of each order was determined and the results are listed in tables 3 and 4 . There were significantly fewer branches of fifth and sixth order in the superior frontal region of the alcoholics. Fourth order in both regions and fifth and sixth order in the motor cortex of the alcoholics show reduced number of branches, but these were not statistically significant. Lower order branches were not reduced. There were significan- 
Table 3 Mean number and length of terminal dendritic branches 2nd to 8th order

\begin{tabular}{|c|c|c|c|c|}
\hline \multirow[b]{2}{*}{ Order } & \multicolumn{4}{|c|}{ Superior Frontal Cortex } \\
\hline & $\begin{array}{l}\text { Number of branches } \\
\text { Control }\end{array}$ & Alcoholic & $\begin{array}{l}\text { Mean length } \\
\text { Control }\end{array}$ & Alcoholic \\
\hline $\begin{array}{l}\text { 2nd } \\
\text { 3rd } \\
\text { 4th } \\
\text { 5th } \\
\text { 6th } \\
\text { 7th and 8th }\end{array}$ & $\begin{array}{r}119 \\
496 \\
755 \\
387 \\
123 \\
19\end{array}$ & $\begin{array}{c}140 \\
534 \\
717 \\
307^{\circledR} \\
77^{\circledR} \\
16\end{array}$ & $\begin{array}{l}45.3(2.7) \\
43.9(1.4) \\
41.3(1.0) \\
42.6(1.4) \\
36.6(2.2) \\
27.4(4.8)\end{array}$ & $\begin{array}{ll}37 \cdot 9^{\star} & (2 \cdot 2) \\
38 \cdot 9^{\star} & (1 \cdot 2) \\
33 \cdot 6^{z} & (0 \cdot 9) \\
33 \cdot 2^{3} & (1 \cdot 4) \\
31 \cdot 4^{\star} \quad(3 \cdot 4) \\
38 \cdot 1 \quad(11 \cdot 5)\end{array}$ \\
\hline
\end{tabular}

Mean (SEM)

$\mathrm{P}=$ significance value determined by the Mann-Whitney test for non-parametric statistics

^P $<0.05$

@P $<0.01$

$=\mathrm{P}<0.001$

tly more second order terminal branches in the alcoholic group.

There were no significant differences between the alcohol and control groups in any of the intermediate dendritic branch lengths using the Student's $t$ test.

Regression analyses were performed on the data from both regions of the controls and alcoholics with respect to age. A significant relationship was found between age and total dendritic length, number of branches and maximal width of dendritic field in both regions of the controls and alcoholics.

Multivariant analysis of variance revealed that the variables were not closely related and discriminant analysis revealed that the width of the dendritic field was the most useful variable in measuring dendritic arbor shrinkage (coefficient $=-.772$ for frontal; 489 for motor).

\section{Discussion}

This study addresses the question of dendritic changes in cortical neurons in human chronic alcoholics. Results show that the alcoholic group, when compared with age and sexmatched controls, have a significantly reduced basal dendritic arborisation of pyramidal neurons of similar size lying in layer III of the frontal and motor cortex. The changes appear to be related to alterations in the terminal branches of the dendrites and not in the intermediate segments (as defined in fig 3). The alterations in number and length of dendrites, particularly the terminal branches, is in keeping with current theories on dendritic plasticity. Such plasticity means that neuronal dendritic arbors are continually changing and adapting by retraction and expansion in response to changes in function and environment. In an experimental rat model McMullen et a ${ }^{20}$ have demonstrated retraction and expansion of basilar dendrites of hippocampal pyramidal neurons after chronic alcohol intoxication and subsequent abstinence respectively.

In a recent review Scheibel ${ }^{21}$ commented that there is evidence that the process of: progressive plastic dendritic changes may continue throughout life and that these changes principally involve the terminal branches. Fritschy and Gareg ${ }^{22}$ in their study of the visual system of the marmoset also noted that these terminal dendritic segments are the most plastic during development. The dendritic structure of the neuron provides an enormous membrane surface area for the reception of afferent information and interaction with other neurons. Hence contraction of this arbor is a likely explanation for the cognitive deficits which have been noted in chronic alcoholic patients. ${ }^{23}$ However, most of the cognitive deficits are referable to the frontal lobes. ${ }^{5}$ Such a pattern of selective cortical damage is not seen in this study in that the dendritic arbor shrinkage is approximately the same in frontal and motor cortex. It should be noted, however, that there were significantly fewer fifth and sixth order terminal branches only in the frontal cortical neurons (tables 3 and 4). The numbers of cortical neurons are reduced in the frontal lobe in alcoholic patients whereas they are normal in the motor cortex. ${ }^{7}$

In addition to a loss of neurons in the superior frontal cortex neuronal shrinkage, as indicated by a reduced mean cell body area, has

Table 4 Mean number and length of terminal dendritic branches 2 nd to 8th order

\begin{tabular}{|c|c|c|c|c|}
\hline \multirow[b]{2}{*}{ Order } & \multicolumn{4}{|l|}{ Motor Cortex } \\
\hline & $\begin{array}{l}\text { Number of branches } \\
\text { Control }\end{array}$ & Alcoholic & $\begin{array}{l}\text { Mean length } \\
\text { Control }\end{array}$ & Alcoholic \\
\hline $\begin{array}{l}\text { 2nd } \\
\text { 3rd } \\
\text { 4th } \\
\text { 5th } \\
\text { 6th } \\
\text { 7th and 8th }\end{array}$ & $\begin{array}{r}67 \\
343 \\
470 \\
249 \\
59 \\
8\end{array}$ & $\begin{array}{r}120 \\
364 \\
440 \\
215 \\
47 \\
10\end{array}$ & $\begin{array}{l}57 \cdot 2(4 \cdot 4) \\
47 \cdot 8(1.9) \\
42 \cdot 8(1 \cdot 4) \\
41 \cdot 1(1 \cdot 7) \\
43 \cdot 1(3 \cdot 6) \\
24 \cdot 6(5 \cdot 5)\end{array}$ & $\begin{array}{ll}34 \cdot 6^{3} & (2 \cdot 4) \\
37 \cdot 3^{\mathrm{s}} & (1 \cdot 4) \\
33 \cdot 2^{\mathrm{s}} & (1 \cdot 2) \\
36 \cdot 1^{(} & (2 \cdot 0) \\
27 \cdot 5^{\mathrm{a}} & (3 \cdot 6) \\
37 \cdot 4 & (7 \cdot 6)\end{array}$ \\
\hline
\end{tabular}


been demonstrated in the frontal superior, frontal cingulate and motor cortices of alcoholics. ${ }^{78} \mathrm{~A}$ change in mean neuronal cell body area was not found in this study, however, and this is probably due to the small number of cell bodies measured.

An alternative explanation is that the changes in the dendritic arbor precede changes in the neuronal cell body such as shrinkage.

In a Golgi study of cerebellar atrophy in chronic alcoholism Ferrer et al $^{17}$ showed that Purkinje cells from the tips of the folia of the rostral vermis had a $32 \%$ reduction in the length of the dendritic tree when compared with control cases. There are no quantitative Golgi studies of cerebral cortex in alcoholics although Ferrer $e t a l^{4}$ have noted a decrease in the number of dendritic spines on cortical neurons in chronic alcoholic patients. However, experimental models exist for both in utero exposure to alcohol ${ }^{131425}$ and adult exposure. ${ }^{151626}$ Following exposure of adult rats to alcohol, quantitative studies of cerebellar Purkinje cells have shown a generalised retraction of the dendritic arbor..$^{1516}$ Pentney ${ }^{15}$ found that Purkinje cells from five month old rats were not susceptible to a ten week period of alcohol but 14 month old rats were. Tavares et al, ${ }^{16}$ using a similar model showed that there was a reduction of all measured parameters of the dendritic arborisation of Purkinje cells. The dendritic field was reduced by almost $50 \%$ and total branch length by $60 \%$ after eighteen months of alcohol ingestion. They concluded that the major determinants of degree of Purkinje cell atrophy was duration of alcohol exposure.

McMullen et a ${ }^{20}$ used a similar model to study the effect of chronic ethanol consumption on the dendritic arborisation of hippocampal pyramidal neurons. After five months of consumption there was a significant decrease in the number of second order basilar dendrites. Perhaps an even more important finding in this study was that in rats which had been withdrawn from alcohol for two months there was evidence of lengthening and new branching of distal basilar dendrites in the third, fourth and fifth order segments. This appears to be the first pathological data to provide an explanation for the reversibility of alcohol brain damage which has been repeatedly demonstrated by sequential CT scan studies in some abstinent alcoholics. ${ }^{27-29}$ However, this is unlikely to be the sole type of reversible damage as it does not explain the fact that alcohol brain shrinkage largely relates to a loss of white matter..$^{63031}$ This concept of reversible white matter damage is supported by brain density measurements which are low in chronic alcoholics $^{32}$ and increase after several months of abstinence. ${ }^{33}$

Durand $e t a l^{34}$ used an alternative technique to study the dendritic alterations induced by ethanol in rat hippocampal granule cells. They injected horseradish peroxidase (HRP) intracellularly which completely fills the soma, dendrites and axon which allows visualisation and quantitation of the dendritic arbor. The results of the study showed a decrease in the number of dendrites in the proximal region of the tree but a significant increase in the distal portion of the tree in ethanol fed rats. Thus the effects of ethanol on dendritic arborisation appear to be extremely complex and may affect different types of neurons in different ways.

Many other physiological and pathological phenomena can influence the dendritic arborisation of neurons. Our study showed an increase in the dendritic arborisation with increasing age in both the control and alcoholic groups. The results of Golgi studies of agerelated effects on cortical neurons appear to be conflicting. Some studies have shown retraction of the arbors ${ }^{111235}$ with increasing age whilst others have shown expansion of the arbors. ${ }^{1036}$ All qualitative studies ${ }^{1112}$ reported a retraction of dendritic arborisation with increasing age. We have found qualitative evaluation of dendritic arbor size to be unreliable and we were unable to distinguish between matched control and alcoholic cases, despite highly significant reductions in the total dendritic length, number of branches and width of dendritic field in alcoholic cases. Quantitative studies of age-related changes are also conflicting. ${ }^{103536}$ There are, however, differences in methodology that may explain the disparities. Quantitative studies reporting a decrease in dendritic arborisation with increasing age concentrated on layer $\mathrm{V}$ neurons, ${ }^{35}{ }^{37}$ while those reporting an increase examined neurons from layers II and III..$^{1036}$

Other physiological manipulations can influence dendritic arborisation. Interference with either afferent ${ }^{38}$ or efferent ${ }^{39}$ pathways can cause a reduction in the dendritic arbor. Manipulation of the environment, so that cortical neurons are either stimulated or deprived can alter dendritic arborisation of cortical neurons significantly. ${ }^{4041}$ Such factors may play a role in the alcoholic patients.

The question of the pathogenetic mechanisms underlying the dendritic changes is important in that several of our cases had other complicating medical conditions such as cirrhosis of the liver (two cases) or Wernicke's encephalopathy (three cases). There were too few cases to draw any conclusions on the dendritic arbors of these groups.

No specific studies have been carried out on cases of Wernicke's encephalopathy which is caused by vitamin $\mathbf{B}_{1}$ deficiency. However, numerous studies have been directed at the effects of undernutrition on dendritic development. ${ }^{42-44}$ All of these studies relate to the immature nervous system and thus may not be relevant to changes in adults. Both pre and post-natal undernutrition in experimental models causes a significant reduction in dendritic arborisaton when compared with controls. This may represent a delay in maturation because the changes are at least partially reversible following resumption of a normal diet. ${ }^{42} 43$ This emphasises the point that alcohol per se (or its metabolites) may not be the most important pathogenetic factor in the production of central nervous system damage in chronic alcoholics. Other factors such as nutritional deficiency states and liver failure may 
play important roles. Animal models of these complex interactions may help in answering this important question.

This work was supported by the National Health and Medical Research Council, Grant 885394 and the Clive and Vera Ramiacotti Foundations. The authors are grateful to Mrs Jillian Kril and Mr Eric Smyth for their help.

1 Harper CG, Blumbergs PC. Brain weights in alcoholics. $J$ Neurol Neurosurg Psychiatry 1982;45:838-40.

2 Torvik A, Lindboe CF, Rodge S. Brain lesions in alcoholics: a neuropathological study with clinical correlations. J Neurol Sci 1982;56:233-48.

3 Harper C, Kril J. Brain atrophy in chronic alcoholic patients: a quantitative pathological study. J Neurol Neurosurg a quantitative pathological
Psychiatry 1985;48:211-7.

4 Carlen PL, Wilkinson DA, Wortzman G, et al. Cerebral atrophy and functional deficits in alcoholics without clinically apparent liver disease. Neurology 1981;31: 377-85.

5 Walsh KW. Alcohol related brain damage: an hypothesis. Australian Drug/Alcohol Review 1983;2:84

6 Harper CG, Kril JJ, Holloway RL. Brain shrinkage in chronic alcoholics: A pathological study. Br Med $J$ 1985;290:501-4

7 Harper C, Kril J, Daly J. Are we drinking our neurones away? Br Med J 1987;294:534-6.

8 Kril JJ, Harper CG. Neuronal counts from four cortical regions in alcoholic brains. Acta Neuropathologica 1989;79:200-4.

9 Harper C, Kril J. Patterns of neuronal loss in the cerebral cortex in chronic alcoholic patients. $J$ Neurol $S_{c i}$ cortex in ch

10 Buell SJ, Coleman PD. Quantitative evidence for selective dendritic growth in normal human ageing but not in senile dementia. Brain Res 1981;214:23-41.

11 Scheibel ME, Lindsay RD, Tomiyasu U, Scheibel AB. Progressive dendritic changes in ageing human cortex. Exp Neurol 1975;47:392-403.

12 Mervis R. Structural alterations in neurons of aged canine neocortex: A Golgi study. Exp Neurol 1978;62:417-32.

13 Davies DL, Smith DE. A golgi study of mouse hippocampal cal pyramidal neurons following perinatal ethanol cal pyramidal neurons following peri

14 Hammer RP, Scheibel AB. Morphologic evidence for a delay of neuronal maturation in fetal alcohol exposure. Exp of neuronal maturation

15 Pentney RJ. Quantitative effects of ethanol on Purkinje cell dendritic tree. Brain Res 1982;249:397-401.

16 Tavares MA, Paula-Barbosa MM, Gray EG. A morphometric Golgi analysis of the Purkinje cell dendritic tree after long-term alcohol consumption in the adult rat. J Neurocytol 1983;12:939-48.

17 Ferrer I, Fabregues I, Pineda M, Gracia I, Ribalta. A Golgi study of cerebellar atrophy in human chronic alcoholism. Neuropathol Appl Neurobiol 1984;10:245-53.

18 Brodmann K. Vergliechende Localisation der Grosshinrinide in ihren Prinzipen dargestellt auf Grund de Zellenbaues. Leipzig: JA Barth, 1909.

19 Mehraein P, Yamada M, Tarnowska-Dzidusko E. Quantitative study on dendritic spines in Alzheimer's disease and senile dementia. In: Kreutzberg GW, ed. Advances in and senile dementia. In: Kreutzberg GW, ed. Advanc

20 McMullen PA, Saint-Cyr JA, Carlen PL. Morphological alterations in rat CAl hippocampal pyramidal cell dendrites resulting from chronic ethanol consumption and withdrawal. J Comp Neurol 1984;225:111-8.
21 Scheibel AB. Dendritic Changes In: Reisberg B, ed. Alzheimers disease. London: Collier MacMillan, 1983:69-73.

22 Fritschy JM, Gareg LJ. Quantitative changes in morphological parameters in the developing visual cortex of the marmoset monkey. Dev Brain Res 1986;29:173-88.

23 Tarter RE, Edwards KL. Neuropsychology of alcoholism. In: Tarter RE, Van Theil DH, eds. Alcohol and the brain: chronic effects. New York: Plenum, 1985:217-42.

24 Ferrer I, Fabregues I, Rairiz J, Galofre E. Decreased numbers of dendritic spines on cortical pyramidal neurons in human chronic alcoholism. Neurosci Lett 1986;69: in human.

25 Pentney RJ, Cotter JR, Abel EL. Quantitative measures of mature neuronal morphology after in utero ethanol exposure. Neurobehav Toxicol Teratol 1984;6:59-65.

26 Riley JN, Walker DW. Morphological alterations in hippocampus after long-term alcohol consumption in mice. Science 1978;210:646-48.

27 Artmann $H$. Reversible enlargement of cerebral spinal fluid spaces in alcoholics. $A J N R$ 1981;2:23-7.

28 Carlen PL, Wortzman G, Holgate RC, Wilkinson DA, Rankin JG. Reversible cerebral atrophy in recently abstinent chronic alcoholics measured by computed tomographic scans. Science 1978;200:1076-8.

29 Cala LA, Jones B, Mastaglia FL, Wiley B. Brain atrophy and intellectual impairment in heavy drinkers: a clinical, psychometric computerised tomography study. Aust NZJ Med 1978;8:147-53.

30 De La Monte SM. Disproportionate atrophy of cerebral white matter in chronic alcoholics. Arch Neurol 1988;45:990-2.

31 Harper CG, Kril JJ. Corpus callosal thickness in alcoholics. Brit $J$ Addict 1988;83:577-80.

32 Harper CG, Kril JJ, Daly JM. The specific gravity of the brains of alcoholic and control patients: a pathological study. Brit J Addict 1987;82:1349-54.

33 Golden CJ, Graber B, Berg I, Coffman J, Bloch S. Difference in brain density between chronic alcoholic and Difference in brain density between chronic
control patients. Science 1981;211:508-10.

34 Durand D, Saint-Cyr JA, Gurevich N, Carlen PL. Ethanolinduced dendritic alterations in hippocampal granule cells. Brain Res 1989;477:373-7.

35 Vaughan DW. Age-related deterioration of pyramidal cell basal dendrites in rat auditory cortex. J Comp Neurol 1977;171:501-16.

36 Diamond MC, Connor JR Jr. Plasticity of the ageing cerebral cortex. Exp Brain Res 1982;Suppl 5:36-44.

37 Feldman ML. Aging changes in the morphology of cortical dendrites. In: Terry RD, Gershaw S, eds. Aging. Neurobiology of ageing Vol 3. New York: Raven Press,
1976:211-27.

38 Hedley-Jones $W$, Brynmor-Thomas D. Changes in the dendritic organisation of neurons in the cerebral cortex dendritic organisation of neurons in the cerebral

39 Sumner BEH, Watson WE. Retraction and expansion of the dendritic tree of motor neurons of adult rats induced in dendritic tree of motor neurons of adul
vivo (letter). Nature 1971;233:273-5.

40 Coleman PD, Riesen AH. Environmental effects on cortical dendritic fields. I. Rearing in the dark. J Anat 1968;102:363-74.

41 Valverde F. Rate and extent of recovery from dark rearing in the visual cortex of the mouse. Brain Res 1971;33:1-11.

42 Leuba G, Rabinowicz T. Long term effects of postnatal undernutrition and maternal malnutrition on mouse cerebral cortex. II. Evolution of dendritic branchings and spines in the visual region. Exp Brain Res 1979;37: 299-308.

43 McConnell P. Nutritional effects on non-mitotic aspects of central nervous system development. Prog Brain Res 1981;53:99-108.

44 Bedi KS, Hall R, Davies CA, Dobbing J. A stereological analysis of the cerebellar granule and Purkinje cells of 30 day-old and adult rats undernourished during early postnatal life. J Comp Neurol 1980;193:863-70. 